\title{
A experiência miliciana norte-americana: antimilitarismo ou pragmatismo?
}

Vitor Izecksohn*

Resumo: Este artigo discute a experiência miliciana nas colônias inglesas da América do Norte e nos Estados Unidos durante a primeira república. Enfatizo o papel do antimilitarismo como principal aspecto da experiência militar anglo-americana. Relaciono essa perspectiva à aversão ao despotismo, derivada da tradição política inglesa e ao controle civil sobre os militares. Sublinho as dificuldades encontradas para a criação de um exército profissional e os problemas de coordenação entre o poder central e as autoridades locais e estaduais.

Palavras-chave: Milícias. Estados Unidos. Antimilitarismo. Cidadania. Governo local.

That such a Militia will secure our Liberties, Properties, and Religion. The Liberties we so justly value in this Country are these: that every one may think and write, and say and do whatever he pleases [...] (Short but Serious Considerations. Panfleto anônimo, 1752)

\section{Introdução}

Um dos valores mais estimados da cultura cívica norte-americana é o controle civil sobre os militares. A submissão dos soldados e oficiais a autoridades civis legalmente reconhecidas foi basilar para a constituição da identidade daquela sociedade ao longo dos

\footnotetext{
* Professor do Instituto de História e do Programa de Pós-Graduação em História Social da Universidade Federal do Rio de Janeiro. Financiamento: CNPq; PPGHIS-UFRJ; Gilder Lehrman Center for the Study of Slavery, Resistance \& Freedom. Contato: vizecksohn@gmail.com.
} 
séculos XVII a XIX. Um importante componente dessa identidade foi existência de companhias milicianas, estabelecidas desde os primeiros anos da colonização europeia. Este artigo realizará uma breve discussão sobre a trajetória da organização miliciana na América Continental Inglesa. Analisarei os padrões adotados por essa instituição ao longo do período da colonização e, posteriormente, durante o processo de construção do estado nacional durante a primeira república (1790-1830). Inicialmente investigarei como os colonos organizaram as instituições militares nos dois primeiros séculos do povoamento europeu. Numa etapa posterior, analisarei as conexões entre o desenvolvimento administrativo dessas primeiras instituições e as respostas da sociedade face às tentativas de inovação do período pós-independência. Dessa forma oferecerei uma breve introdução aos problemas sociais e constitucionais que limitaram a expansão de um exército profissional nos Estados Unidos durante a primeira metade do século XIX. O antimilitarismo, na forma da aversão à constituição de organizações militares permanentes, constituiu aspecto importante da cultura cívica das colônias inglesas. Esta situação contrasta com a forte presença militar norte-americana em várias partes do mundo na atualidade.

\section{Os primeiros tempos}

É preciso considerar a diversidade das diferentes regiões que integravam a América Continental Inglesa. Até meados do século XVIII, as colônias compunham um mosaico de coletividades fracamente conectadas umas às outras. As variações regionais nos padrões demográficos, migratórios, religiosos e na organização do trabalho tornam difícil qualquer generalização. ${ }^{1}$ A despeito da enorme diversidade, é possível identificar pelo menos um ponto em comum a todas elas: no panorama colonial, inexistia centralização político-administrativa, ao menos no que dizia respeito à guerra ou aos preparativos para sua execução. Em consonância com essa limitação, as atividades militares nessas regiões envolveram um grau muito menor de centralização e acumulação de poderes coercitivos por autoridades concentradoras do que na Europa continental e 
mesmo na Inglaterra. Assim, em contraste com os esforços europeus por estabelecer o "governo direto", através de uma burocracia forte, a cooperação entre agentes públicos e autoridades locais constituiu a principal característica das normas de defesa no panorama colonial da América inglesa. ${ }^{2}$

A acomodação resultante desse compromisso resultou numa forte dependência governamental em relação às forças auxiliares. Esses grupos localmente organizados seguiam suas lideranças, apoiando as autoridades no fortalecimento da capacidade defensiva ou na manutenção da ordem interna. Foram assim essenciais à execução das demandas imperiais através de territórios que desconheciam uma organização burocrática definida, transmitindo comandos e regulando ambas: a política colonial e, posteriormente, a política nacional, através de barganhas complexas. A natureza dessas barganhas e as demandas que elas geraram fornecem evidências para a compreensão das percepções da população sobre seus direitos e obrigações em relação ao governo Imperial/Nacional.

\section{O Desenvolvimento das instituições militares nas colônias norte-americanas}

A evolução das instituições militares norte-americanas a partir do século XVII foi descentralizada, confusa e precária. Tanto no seu formato como na estrutura de seu funcionamento, os arranjos militares norte-americanos (derivados como eram dos ingleses) contrastavam com as organizações adotadas pelas monarquias mais centralizadas da Europa moderna, especialmente aquelas estabelecidas na sua porção ocidental. A autoridade dos estados europeus do século XVII foi crescentemente relacionada à capacidade de organizar e manter exércitos permanentes. Esse movimento foi potencializado pela introdução de novas tecnologias, que aumentaram os custos do aparato militar. Essas inovações eram excessivamente caras para os orçamentos de cidades-estado ou de confederações, circunstância que reforçou o papel das instituições centralizadas, que se mostraram melhor preparadas para lidar com a tributação, a militarização e a mobilização de grandes contingentes populacionais. ${ }^{3}$

Anos 90, Porto Alegre, v. 22, n. 41, p. 83-111, jul. 2015 
A Revolução Militar, termo adotado para explicar esse conjunto de transformações, acelerou o desarmamento da sociedade, reforçando o papel do estado Nacional como a estrutura efetivamente capaz de impor e coordenar a mobilização militar. Através de ondas sucessivas de acumulação de poder, os monarcas de diversos estados mostraram-se capazes de impor sua liderança tanto à aristocracia fundiária quanto às autoridades eclesiásticas, ainda que o nível de sucesso nessas empreitadas tenha variado caso a caso. Houve assim um movimento claro na direção do fortalecimento das monarquias a expensas de barões, padres e habitantes citadinos. ${ }^{4}$

Enquanto as monarquias da Europa ocidental reforçavam suas estruturas guerreiras e especializavam os profissionais que as operavam, os colonos da América continental reviveram a experiência das milícias, que na Europa se tornara anacrônica. O revigoramento dessa instituição no panorama americano resultou de vários fatores, entre eles: a inexistência de uma herança feudal, a escassez geral de recursos e a falta de mão de obra, que prevaleciam nas treze colônias. A defesa em vilas e cidades dispersas foi associada inicialmente ao autogoverno, à disseminação do uso de armas de fogo pela população e à mobilização rápida dos chamados "minutemen". 5 Ela consistia num elemento essencial da cultura cívica e do não conformismo estabelecidos pelos primeiros colonizadores. Nesse ambiente, os cidadãos tornavam-se soldados, na expressão de John Whiteclay Chambers, "Quando queriam". 6

Durante o primeiro século da colonização, a guerra era intermitente. Ela envolvia os colonos em lutas contínuas contra grupos indígenas e representantes de impérios rivais: franceses, espanhóis e holandeses, que ali pretendiam se estabelecer. ${ }^{7}$ Inexistia um front definido e os sucessivos combates eram geralmente acompanhados por remoções e breves períodos de paz, através do que Chambers classificou como "modelo de fixação". Neste arquétipo, a guerra e o local de trabalho agrícola encontravam-se fortemente interligados. À medida que a fronteira se expandia, os repertórios da violência tornavam-se mais brutais. Eles envolviam o extermínio dos rivais, o arrasamento de vilas e aldeias, o saque, a destruição sistemática das colheitas e a retaliação por ataques prévios. Um colono da Virgínia descreveu o estado de tensão permanente que prevalecia entre 
os seus concidadãos durante o ataque dos Opechancanough em 1681: "Quando saímos pela manhã, não sabemos se retornaremos. Trabalhamos com a enxada numa mão e a espada na outra [...]". Outro colono, baseado na baía Nagarransett (Rhode Island), descreveu um ataque efetuado contra os Pokanoket, em dezembro de 1675: “[...] tendo queimado todas as suas tendas, assim como todo o milho que pudemos encontrar, eles, portanto têm menos abrigo e menos subsistência, [Consequentemente] sua miséria é muito agravada pela grande nevasca".?

A organização miliciana reproduzia as hierarquias sociais locais da mesma forma que afirmava práticas paroquiais, fortalecendo a primazia do poder local. Na América britânica, a formação da sociedade precedeu, em larga escala, a formação do estado, levando organizações locais a cumprir muitas das funções que na tradição europeia foram desempenhadas por braços estatais. O serviço militar refletiu essa experiência através dos vínculos que de fato cimentavam as lealdades: filiação religiosa, participação em conselhos deliberativos, o desejo de ascensão social ou simplesmente o medo de ataques indígenas ou rebeliões escravas. A mobilização local estava associada ao serviço militar e às normas de sobrevivência física dos colonos das fronteiras. ${ }^{10}$ Nas milícias desses primeiros tempos, o cidadão e o soldado amalgamavam-se no mesmo corpo, pois estava em jogo a defesa das suas comunidades, vidas e propriedades, conformando o que John Shy denominou como "A era da sobrevivência". ${ }^{11}$ Esse padrão, inicialmente desenvolvido nas colônias da região da Nova Inglaterra, foi aos poucos adotado pelas demais colônias, com as devidas variações regionais à experiência original. Essas diferenças eram mais expressivas nas colônias do sul, que possuíam um número maior de escravos e nas quais a tensão social também se fazia sentir de uma forma mais intensa através da desigualdade social fomentada por uma presença pronunciada de servos brancos. ${ }^{12}$

As forças militares coloniais divergiam na sua organização, nos períodos de serviço e nas modalidades de recrutamento e treinamento. Exceto por emergências, elas reforçaram a conexão entre o serviço militar e a homogeneidade racial, entendendo esta última pelo pertencimento à condição de homem branco adulto. O sistema eximia, pelos menos nominalmente, os escravos, os índios, as mulheres, os 
clérigos, os estudantes universitários e aqueles considerados muito jovens ou muito velhos para servir. A ação combinada entre oficiais de altos e médios escalões de um lado, e as lideranças locais, de outro, reforçavam a influência da família e o status comunitário na designação das lideranças milicianas. Esses voluntários serviam nas mesmas unidades dos seus oficiais, através de uma rede complexa de relações de parentesco e de trabalho que dava sentido à hierarquia, reforçando os critérios de bravura: afinal, além da defesa da comunidade havia também que mostrar coragem a vizinhos e parentes. Dessa forma, o treinamento dos milicianos combinava elementos de paradas militares, feriados comunitários e serviço eclesiástico. Constituía, portanto, um ritual sobre as tensões sociais e a unidade comunitária, refletindo e afirmando a identidade dos colonos. Ele afirmava a missão do "povo escolhido por deus" na América, celebrando, simultaneamente o individualismo do jovem comum e reafirmando a solidariedade comunitária que sustentava a união de uma população tumultuosa e diversa.

Exceto durante os períodos de grande perigo, os homens brancos adultos compunham a maior parte do contingente. Negros livres e escravos somente esporadicamente eram admitidos como soldados regulares ou substitutos, já que sua presença nas fileiras em tempos de paz afrontava os estereótipos raciais, que conectavam o serviço militar com a masculinidade, a cidadania e a condição de branco. Ainda que em muitas ocasiões escravos seguissem seus senhores em alistamentos informais, as milícias e as forças coloniais na América inglesa habitualmente ofereceram um ambiente etnicamente mais homogêneo que instituições semelhantes em outras áreas das Américas. Ofereciam também um espaço de forte exclusão de minorias. A segregação era latente, obstruindo as possibilidades de ascensão nas fileiras dos negros livres e dos índios assimilados. $\mathrm{Na}$ Virginia, o serviço na milícia foi proibido para os negros livres a partir de 1640. Em outras colônias, nem chegou a ser concedido. ${ }^{13}$

A estrutura militar, que colocava todos os brancos pelo menos um degrau acima dos grupos racialmente discriminados, simultaneamente permitia a jovens artesãos e pequenos proprietários brancos as oportunidades para ganhar algum dinheiro, viajar para a fronteira e, ocasionalmente, estabelecerem-se nas terras incorporadas. Ela também 
possibilitava contatos pessoais que poderiam ser úteis no comércio, especialmente para jovens fazendeiros, interessados em melhorar suas habilidades mercantis ou para filhos de famílias numerosas, sem muitas chances de permanecer nas terras de seus ancestrais.

A Virgínia e as Carolinas apresentavam um cenário diferente, com uma presença mais forte de destituídos. Na Virgínia, durante o século XVII, os grupos mais abastados das elites locais excluiriam gradualmente das fileiras os servos e os brancos pobres. Eles temiam que, uma vez armados, os setores empobrecidos promovessem rebeliões contra a minoria afluente da colônia. Para repelir os índios nas fronteiras cada vez mais distantes, a elite passou a pagar, armar e suprir unidades assalariadas. Por volta de 1680, somente aqueles aptos a se armarem e a se equiparem às suas próprias custas serviam na milícia. Essa situação praticamente eliminou os brancos pobres de quase todas as tarefas militares, exceto os serviços de emergência. Uma "milícia aburguesada" estava sedimentada por volta de 1690, atuando como uma força policial, encarregada de manter a ordem interna. ${ }^{14}$

\section{O serviço militar na era da competição Imperial}

Ao longo do século XVIII, mudanças substantivas nas práticas militares foram introduzidas. Elas derivaram da intensificação na competição entre os Impérios Europeus. Uma série de conflitos dinásticos ecoou no continente americano destacando-se: a Guerra de Sucessão do Trono Espanhol (1702-1714), conhecida nos EUA como a "Guerra da Rainha Anne" e, principalmente, a Guerra dos Sete Anos, também chamada de "Guerra contra os Franceses e os Índios" (1756-1763). Esta última constituiu o primeiro conflito internacional em escala global. Enfrentando desafios em continentes diferentes, a Coroa Britânica necessitou do apoio dos seus súditos americanos para enfrentar as ameaças representadas pelas forças francesas. A criação de uma nova instituição, os exércitos provinciais, foi a principal resposta de Londres a essa percepção. As autoridades da Coroa organizaram essas forças semiprofissionais para lidar com o acirramento na disputa por territórios na América do Norte e no Caribe. Num período de intensa competição intercolonial,

Anos 90, Porto Alegre, v. 22, n. 41, p. 83-111, jul. 2015 
as monarquias europeias lutavam para modernizar a capacidade defensiva de seus impérios em territórios distantes. Isso era feito principalmente através da cooptação dos súditos, fossem colonos, escravos ou nativos. ${ }^{15}$ Para compelir a população branca da América Inglesa a servir por longos períodos, as autoridades britânicas instituíram gratificações que tornaram mais atrativo o serviço nessas companhias auxiliares.

Diferentemente do que se passava com os soldados profissionais ingleses (redcoats), os regimentos provinciais eram constituídos basicamente por voluntários: jovens empobrecidos, aprendizes, filhos de artesãos ou de pequenos fazendeiros, em busca de oportunidades. O recrutamento de voluntários nessas forças provinciais marcou o fim do período de transição da cultura guerreira americana. Os colonos tinham percorrido um longo caminho desde o estabelecimento inicial de normas coletivas de autodefesa até chegarem aos processos de motivação individual e especialização que os levaram a integrar organizações de combate mais sofisticadas. Após décadas de deslocamentos causados por combates localizados, a guerra havia se tornado menos ameaçadora para a atividade econômica, exceções feitas às vilas localizadas nas fronteiras.

O estabelecimento dessas forças semiprofissionais não destruiu o paroquialismo nas fileiras. A primazia de organizações locais sobreviveu a eventuais mudanças na utilização das tropas. De acordo Harold Selesky, em Connecticut, esses regimentos retiveram muitas das características da milícia original, incluindo o treinamento rudimentar, a disciplina frouxa e a escolha dos oficiais, principalmente devido à sua popularidade entre os soldados. ${ }^{16}$ Durante o século XVIII, o parentesco ainda desempenhava um papel fundamental na estrutura e na disciplina das unidades militares, reforçando a posição dos líderes comunitários sobre seus seguidores. Como demonstrado por Fred Anderson na sua pesquisa sobre Massachusetts colonial, o deslocamento, no sentido da mobilidade espacial, era parte da experiência dos colonos, promovendo oportunidades de entrar em contato com outras regiões e realidades diferentes. Como súditos do Império Britânico, esses homens alistavam-se nas fileiras coloniais porque essa tarefa acabava auxiliando seus próprios interesses, pelo menos temporariamente:

Anos 90, Porto Alegre, v. 22, n. 41, p. 83-111, jul. 2015 
Os soldados de Massachusetts durante a Guerra dos Sete Anos [...] não se constituíam em proletários coloniais. Pelo contrário, eles eram produto de uma economia que constantemente gerava homens que se encontravam temporariamente disponíveis para o serviço militar. ${ }^{17}$

Numa sociedade com altas taxas de reprodução, o recrutamento desses indivíduos disponíveis não afetava o trabalho de famílias numerosas, tampouco a economia de comunidades dependentes da pesca ou da agricultura, que de outra forma poderiam se ressentir da perda causada por ausências relativamente longas de seus filhos, irmãos ou vizinhos. Para esses voluntários, o serviço nessas companhias gerava uma renda suplementar que validava a submissão temporária a oficiais desconhecidos, permitindo uma independência relativa que assegurava oportunidades para futuros empreendimentos. ${ }^{18}$

Um excesso de homens temporariamente disponíveis fornecia aos ingleses os soldados auxiliares de que aqueles precisavam para sustentar longas campanhas, mas a disciplina militar era efetivada de forma heterodoxa, segundo os costumes locais. Ela era mantida através de apelos à honra ou à coragem, tais como os juramentos de aprendizes ou as exortações à confiança mútua, comuns à experiência miliciana. Harold Selesky destacou os limites da disciplina nos exércitos provinciais ao descrever a situação das tropas de Connecticut durante a Guerra de Sucessão Espanhola: "Enquanto os líderes permitiam que oficiais multassem os desertores e neles infligissem castigos corporais, eles continuaram cautelosos ao não demandar mais dos recrutados do que aquilo que o consenso comunitário permitiria"19 (SELESKY, 1990 , p. 74). O empenho, fosse individual ou coletivo, compensaria a falta de hierarquia militar, especialmente em circunstâncias nas quais os interesses locais prevalecessem. De acordo com John Shy, "O esforço efetivo na mobilização vinha da própria sociedade, de dezenas de comunidades coesivas o suficiente para repelir a dissensão e compelir [seus membros] a uma resposta"20 (SHY, 2007, p. 10).

Para aqueles que se alistavam voluntariamente, os termos de serviço eram menores que para os soldados regulares do exército britânico: um ou dois anos sob contratos que estipulavam a baixa imediata quando o período expirasse. A natureza contratual desses 
alistamentos algumas vezes constrangeu os comandantes imperiais britânicos, que subscreviam noções muito diferentes sobre o caráter do serviço militar. Os oficiais britânicos percebiam que a sua autoridade era limitada pelo que consideram "excessos democráticos": os colonos negociando para si mesmos as melhores condições de serviço e dando baixa assim que seus contratos expiravam. O Major General Braddock discorreu sobre a qualidade das tropas provinciais, salientando que as mesmas eram compostas por homens "[...] muito indiferentes, [mas] esse país não proporciona nada melhor”. Outros oficiais viam os colonos como "Um povo obstinado e ingovernável, e completamente ignorante sobre a natureza da subordinação". ${ }^{21}$

Diferentes concepções sobre a natureza do serviço militar limitavam a imposição de uma disciplina mais forte. Por mais críticos que os comandantes britânicos pudessem ser em relação aos costumes dos habitantes coloniais, eles entendiam que a cooperação local era valiosa o suficiente para justificar o sacrifício das normas disciplinares. Mas, sem esses padrões, era também muito difícil construir um espírito de corpo, baseado no profissionalismo, numa disciplina rígida e em cadeias de comando hierarquizadas, especialmente importantes nas lutas contra os regimentos franceses. Poucos voluntários viam o serviço militar como uma carreira, circunstância que impediu a formação de mentalidades marciais entre os colonos, salvo poucas exceções. Como observado por Charles Royster, "Os americanos eram agricultores, comerciantes, mecânicos e fazendeiros - não soldados - e eles pretendiam permanecer assim". ${ }^{22}$

Dessa forma, as tropas recrutadas na América inglesa não podiam ser completamente isoladas do seu ambiente doméstico, mesmo quando mobilizadas para as fronteiras. Consequentemente, as relações entre os voluntários e os oficiais permaneceram num tom informal e paternalista, tornando a disciplina muito menos efetiva que nos exércitos europeus. As hierarquias militares baseadas na patente, no desempenho, no treinamento e na subordinação à autoridade tiveram que ser adaptadas às circunstâncias e às motivações presentes em cada uma das colônias eventualmente envolvidas nos combates.

A aversão às práticas hierárquicas dos exércitos profissionais não acarretava, entretanto, em desprezo pela presença de tropas inglesas nas principais cidades costeiras. $\mathrm{O}$ antimilitarismo da primeira 
metade do século XVIII constituiu, sobretudo, um comportamento relativo. No ambiente complexo da guerra intercolonial, a hostilidade da população aos exércitos regulares era mais retórica que real. A presença dos redcoats estacionados em cidades e vilas dinamizou mercados, estimulando empreendedores rurais e urbanos. Muitos colonos beneficiaram-se, portanto, da presença de tropas inglesas. As vitórias contra os competidores franceses e de seus aliados indígenas forneceram outro elemento de ligação entre os soldados profissionais ingleses e a população local, especialmente quando as guerras permitiram a extensão da fronteira além dos Apalaches, abrindo amplos espaços para a potencial colonização. Portanto, a cooperação, além de aumentar as oportunidades econômicas, livrou os colonos de uma ameaça externa significativa, uma vez que a presença francesa foi substancialmente reduzida na América do Norte na segunda metade do século XVIII.

\section{Rupturas}

As tensões voltariam a crescer quando as autoridades Britânicas procuraram expandir seu comando sob as colônias acostumadas a um grau elevado de autonomia. A ocupação de cidades costeiras, especialmente a primeira ocupação Britânica de Boston, em 1769, constituiu o ponto de mutação. Em quinze de abril de 1769, o Conselho de Massachusetts, escrevendo ao Conde de Hillsborough, secretário de estado para as Colônias Americanas, reclamou que as circunstâncias que marcaram o desembarque das tropas em Boston soavam "[...] como se fosse num país inimigo". ${ }^{23}$ Os colonos paulatinamente afastaram-se do comportamento pragmático, que aceitava a presença de tropas inglesas, retornando à crítica ideológica do século dezesseis: a presença de exércitos permanentes deixou de ser tolerada a partir de então. Mas revoltar-se contra o mais poderoso Império da época requereu o desenvolvimento de forças capazes de resistir ao domínio britânico através da combinação de meios convencionais e anticonvencionais. Ironicamente, a reação contra a ocupação militar britânica requereu a organização de um novo exército, no evento de uma guerra prolongada; uma força capaz de 
ser utilizada em oposição a uma superpotência apoiada por setores locais. A guerra de Independência constituiu igualmente uma guerra civil, na qual uma parte da população, alcunhada como "Tories", tomou partido das forças leais ao rei Jorge VI e da continuidade no Império em oposição aos "Whigs", que lutavam pela independência.

\section{O Exército Continental}

Durante a Guerra de Independência, a mobilização do Exército Continental dependeu de um misto de esforços nacionais e iniciativas locais e estaduais. Ocorreu a mobilização de um contingente permanente, pago, arregimentado através de um alistamento de longo prazo. O Exército Continental era composto por cidadãos soldados, motivados pela causa, mas também por imigrantes irlandeses e alemães, além de índios, servos e pessoas sem endereço ou ocupação fixa, que pouco se importavam com os altos ideais discutidos nos salões, nas tavernas e nas conferências. Esses soldados profissionais lutaram lado a lado com milícias locais e provinciais, cada uma das quais seguindo uma agenda específica.

Da mesma forma como a experiência colonial havia variado de lugar a lugar e de pessoa para pessoa, assim foi com a racionalidade por trás da rebelião contra a Inglaterra. A intensidade da guerra e a disposição de cada colônia para suportar seus efeitos diferiram durante aqueles anos cruciais. De acordo com Edward Countryman:

O movimento revolucionário nunca constituiu uma frente única contra um inimigo. Ele foi uma série de coalizões que se formaram, dissolveram e reagruparam, à medida que a população considerava suas necessidades, suas crenças e a situação em que se encontravam. ${ }^{24}$

O exército regular sofreu permanentemente com a falta de pessoal, de provisões e de recursos. As contribuições de cada uma das colônias eram irregulares e assimétricas; elas variavam de acordo com a movimentação do front, com tensões internas entre as classes e com o grau de coesão local sobre a independência. As deserções e 
constantes baixas do serviço permanentemente esvaziavam as fileiras. Conflitos de responsabilidade envolvendo o exército, o Congresso Continental na Filadélfia e as assembleias coloniais permaneciam sem solução, obstruindo a capacidade do exército para se preparar para longas campanhas. Como a lealdade primária das milícias era para com seus estados de origem, a autoridade do exército era constantemente solapada pelas necessidades locais. O recrutamento de Afro-Americanos, livres ou escravos, constituía uma das questões subordinadas à política local. Os negros compunham uma fonte potencial de novos recrutas para um exército que sofria com a grande escassez de soldados. Mas seu recrutamento era limitado devido aos temores que a presença de escravos armados causava entre a maioria branca. Nesse período havia escravos no Norte e no Sul, além de uma população de negros livres que poderiam ser mobilizados. Era assim particularmente durante os períodos de emergência que os escravos e os índios podiam ser alistados em certos estados. Uma proclamação da assembleia geral do estado de Rhode Island, de acordo com essa máxima, recomendava:

Que todo homem negro, mulato índio ou escravo, em condições de servir deve alistar-se em qualquer dos dois batalhões designados, para servir durante a continuação da presente guerra com a Grã-Bretanha; - Que todo escravo que se alistar estará autorizado a receber todas as gratificações, salários e encorajamentos devidos pelo Congresso Continental a quaisquer soldados alistados nesse serviço. ${ }^{25}$

A proclamação da assembleia de Rhode Island também sugeria que cada escravo alistado deveria ser libertado após dar baixa. Os proprietários seriam compensados por fundos públicos, cujas fontes o referido documento não deixava claras. Emergências, na forma de uma campanha particularmente árdua, justificavam a ocasional subversão da segregação, especialmente quando os Ingleses ocupavam Newport (o principal porto do estado), e a provisão de novos contingentes era incerta. A despeito da brecha aberta, a Assembléia Geral de Rhode Island não estabeleceu um lugar permanente para os veteranos que ocasionalmente serviram, seja seguindo seus senhores, 
seja substituindo brancos ou se ainda alistando-se individualmente. Eles eram vistos como membros temporários de uma instituição cuja coesão racial seria restabelecida assim que as condições permitissem.

Em novembro de 1775, o governador britânico da Virginia, Lord Dunmore prometeu a liberdade aos escravos que deixassem seus senhores, alistando-se nas forças reais. Os escravos do Sul (ainda havia um contingente significativo de escravos nas cidades do Norte) aproveitaram-se das oportunidades abertas pela crise da sociedade colonial para perseguir a sua própria liberdade, inaugurando um padrão que se repetiria por todo o continente americano. A guerra, portanto, permitiu a presença de soldados ex-escravos em ambos os exércitos, criando uma onda emancipatória que permaneceria incompleta. ${ }^{26}$ A posição vulnerável do Sul seria enfatizada anos depois, quando uma carta enviada pelo Comitê de Defesa da Louisiana ao general Andrew Jackson descreveu a região como "Forte pela natureza, mas extremamente fraca pela natureza da sua população". ${ }^{27}$ Certamente a escravidão no Sul foi afetada pelo deslocamento de escravos e pelo caráter particularmente violento de uma guerra civil fratricida, mas não ao ponto de levar a instituição à extinção, como talvez fosse desejado por muitas lideranças dos estados do Norte, entre as quais se incluíam Benjamin Franklin e Alexander Hamilton. A luta pela independência dos Estados Unidos não instilou ideais de igualdade racial ou assimilação entre os cidadãos da nação emergente. Ao final da guerra, os Afro-Americanos, mesmo quando livres, seriam cidadãos subordinados numa ordem social que resguardava uma suposta homogeneidade racial, garantindo demandas igualitárias somente aos cidadãos brancos. Alguns dos veteranos negros ainda conseguiriam receber pensões, mas o caminho para um padrão de cidadania mais inclusivo permaneceu fechado para os negros que apostaram no lado patriota.

\section{O exército após a independência}

O movimento para a criação de um exército permanente e de grande porte poderia ter se consolidado a partir da vitória dos colonos contra o Império Britânico, particularmente à medida que 
o General Washington não fez segredo da sua frustração com a inexperiente e indisciplinada milícia que constituía a base da força armada. No entanto, o principal resultado da vitória dos patriotas foi a rejeição dos principais elementos do desenvolvimento burocrático Europeu, incluindo a constituição de um monopólio legítimo da violência pelo estado nacional.

Durante a guerra de independência, os colonos revoltaram-se contra a imposição de padrões europeus de ordenamento político. Eles também se insurgiram contra o que percebiam como sendo o risco de um poder absoluto, que acreditavam prevalecer na maioria dos estados europeus. Finalmente, os americanos revoltaram-se contra a ameaça de uma mudança no comportamento do poder político, preferindo o consenso local à autoridade imperial, que acreditavam ameaçar a liberdade que seus ancestrais vinham construindo desde o século XVII. Ao final da guerra de independência, o Congresso simplesmente dispensou a maior parte das forças continentais, mantendo apenas um pequeno contingente de não mais de oitocentos soldados em serviço. O exército como instituição foi privado do poder e da influência desfrutadas pelas forças armadas em muitas nações europeias.

Ao longo da década de 1780, uma das questões centrais nas discussões envolvendo a ratificação da Constituição Federal foi o papel constitucional das forças armadas, especialmente os poderes concedidos aos oficiais profissionais, assim como os limites impostos à sua autoridade. De acordo com Samuel Huntignton, os partidários da Constituição não temiam a ameaça de um exército permanente. $\mathrm{O}$ fenômeno do militarismo não era conhecido durante a segunda metade do século XVIII. Os propositores da Constituição temiam o despotismo, especialmente aquele vindo de um estado forte e centralizado, um espectro que assombrava muitos americanos durante o período da primeira república. Os temores atávicos de uma autoridade centralizada e de uma tributação excessiva constituíam as características mais claras da corrente Antifederalista, que se opunha à ratificação da constituição, mas também estavam presentes, ainda que num nível menor, do lado Federalista. ${ }^{28}$ Essa perspectiva não era forte apenas entre os pensadores, ela perpassava todos os setores da cidadania ativa, que participavam da vida política nos primeiros anos da república. ${ }^{29}$ Dessa forma, não sem conflitos, a Constituição divide as responsabilidades 
civis nos assuntos militares em vários níveis administrativos. No sistema Federal, as cláusulas da Milícia dividem o controle das forças militares entre os estados e o poder executivo. No interior do governo nacional, a separação de poderes divide o controle das forças militares entre o Congresso e o presidente. Criou-se, assim, o que Huntington designou como "controle objetivo" dos militares, um conceito que o autor procurou, sem sucesso, aplicar a outras sociedades e contextos.

Resolvida a questão da divisão de poderes entre os estados e o governo central, as lideranças políticas voltaram-se para a relação entre as milícias e o governo central, que havia ficado parcialmente resolvida pela ratificação da Constituição. As milícias forneceriam a base do recrutamento dos soldados, ficando seu controle subordinado aos governadores dos estados e aos chefes políticos regionais. Em 1792, o Congresso aprovou o Federal Militia Act, uma lei que definia a milícia nacional como composta por "cidadãos brancos livres e aptos dos respectivos estados", em consonância com a visão da cidadania política como questão estadual. ${ }^{30}$ Essa lei favoreceu os poderes locais em dois pontos essenciais: ela manteve o controle local sobre as milícias e reforçou as restrições raciais através da exclusão legal de negros e índios do serviço militar. Assim, oficialmente, o serviço nas milícias na nova república independente seria possível apenas para os brancos. Através dessa exclusão, os legisladores reforçavam a concepção de uma nação racialmente homogênea, defendida por cidadãos-soldados protestantes, cuja segurança seria proporcionada por forças locais de dimensão reduzida. Na medida em que a milícia constituía a base da qual os soldados eram enviados para o exército nacional, essas restrições também afetaram a composição social do exército, excetuando os ocasionais guias negros ou indígenas que não faziam parte das tropas regulares. Ao contrário do que se passaria no Brasil anos depois, o processo de independência nos EUA levou a um clareamento das fileiras. ${ }^{31}$ Essa situação foi mantida nas revisões constitucionais da década de 1820. Em 1859, portanto, às vésperas do início da Guerra Civil, o general Nathaniel P. Banks, governador do estado de Massachusetts, vetou legislação que teria permitido o ingresso de negros na milícia, alegando que esta modificação feriria as cláusulas do "Militia Act" que garantiam exclusividade no serviço apenas para os brancos. ${ }^{32}$ 
A facção nacionalista, liderada por George Washington, Alexander Hamilton e George Clinton, fracassou no seu intento de criar um exército permanente e poderoso. Isso ocorreu porque as milícias estaduais forneceram um contrapeso contra o crescente poder do governo federal, que era especialmente temido durante a Era Federalista. De acordo com Chambers, o padrão de mobilização que prevaleceria nesse período incluía três principais componentes: um exército profissional de pequeno porte, algumas unidades da milícia estadual e corpos de voluntários. Essa estrutura prevaleceu porque "[Ela] permitia que um poder central relativamente fraco reforçasse rapidamente o exército para defender a nação". ${ }^{33}$

Os norte-americanos sancionaram instituições descentralizadas para cumprir as funções militares. Eles deram preferência às milícias estaduais porque elas forneciam uma solução de baixo custo para os desafios que eles enfrentavam, mantendo os governadores no controle das atividades milicianas. A Constituição, documento de corte centralizador, simultaneamente proporcionava aos estados uma ferramenta eficiente contra a intervenção federal. A relativa fraqueza do governo federal não ameaçava a integridade territorial porque as raízes do pacto político permaneciam nos estados de onde eram reforçadas através de acordos no Congresso. ${ }^{34} \mathrm{Na}$ ausência de vizinhos poderosos, o sistema miliciano funcionava aparentemente bem. Como observado por Alex de Tocqueville no início dos anos de 1830, as fortunas do país resultavam de uma combinação auspiciosa de isolamento geográfico e capacidade política: "Separado pela geografia, bem como por escolha das paixões do velho mundo, ele não precisa se proteger contra eles nem segui-los". ${ }^{35}$

Nesse panorama, a possibilidade de instituição do recrutamento compulsório alertava os americanos para os piores aspectos das sociedades europeias. A organização miliciana composta por voluntários motivados fornecia um antídoto adequado ao que consideravam como o exemplo do despotismo europeu e uma intrusão indevida dos estado nacional nos assuntos domésticos. Tocqueville observou sobre esse tópico que: "O recrutamento compulsório é tão contrário aos hábitos do povo dos Estados Unidos que eu duvido que qualquer um se arriscaria a propor uma lei como essa". ${ }^{36}$

Anos 90, Porto Alegre, v. 22, n. 41, p. 83-111, jul. 2015 


\section{Problemas e Limites}

Se o sistema podia ser elogiado pelas suas vantagens políticas, os resultados em período de guerra podiam ser bem diferentes. A república dos Estados Unidos, durante suas primeiras décadas de existência, era um ambiente adverso ao recrutamento. Numa sociedade próspera, contando com vastas extensões de terra que foram adicionadas pela compra da Louisiana (1803), poucas pessoas arriscariam-se voluntariamente a assumir os riscos proporcionados pela vida militar, abandonando suas fazendas ou empregos urbanos para abdicar da sua independência individual em função da obediência a uma hierarquia. A escassez de voluntários assombraria os esforços de guerra da república durante a primeira metade do século XIX, demandando um excesso de criatividade por parte de seus líderes emergentes.

Durante o século dezenove, a crescente dependência nas milícias estaduais constantemente atrapalhou o governo federal, tornando a ausência de um exército permanente naquilo que Stephen Skowronek classificou como "um problema permanente". A coordenação entre os interesses militares do governo federal e dos governos estaduais nunca foi completa, criando embaraços à movimentação militar. Quando o presidente James Madison convocou a milícia durante a guerra contra os ingleses, em 1812, os governadores de Massachusetts e Connecticut recusaram-se a cooperar. Eles justificaram essa posição declarando que somente aos estados caberia decidir quando as circunstâncias justificariam o chamado às armas. $O$ governador de Connecticut declarou que a milícia estadual não poderia ser colocada sobre o comando de oficiais federais. ${ }^{37}$ Ainda no mesmo ano, um conflito similar ocorreria quando a milícia de Nova Iorque, estacionada na fronteira do Niagara, recusou-se, em bases constitucionais, a entrar no Canadá em apoio às forças regulares. ${ }^{38} \mathrm{O}$ comandante geral dos exércitos do Niagara reclamou que os poucos homens que se voluntariaram, o fizeram com o objetivo "[...] de cuidar das suas próprias famílias e propriedades, levando-as para o interior [...]", portanto, o mais distante possível da fronteira canadense. ${ }^{39}$

Durante o período anterior à eclosão da Guerra Civil, o exército regular era muito pequeno, variando entre quatro e dezesseis mil soldados, espalhados por várias guarnições distribuídas pelas

Anos 90, Porto Alegre, v. 22, n. 41, p. 83-111, jul. 2015 
fronteiras. Os estados retiveram a responsabilidade sobre quando seus homens poderiam ser chamados, quando poderiam ser enviados, e (algumas vezes) onde serviriam. Para obter esse controle, os governadores contavam com a força dos partidos políticos do chamado segundo sistema partidário, emergindo, no início da década de 1830, uma instituição que nas palavras de Eric. L. McKitric seria: "historicamente a principal agência na mobilização e sustentação do governo americano". ${ }^{40}$ As organizações partidárias proveram a estrutura necessária à transformação de cidadãos em soldados.

Se os partidos políticos possuíam a proeminência, também parece certo que as milícias exerciam forte influência na sociedade, já que as reuniões da milícia "[...] constituíam as maiores aglomerações de pessoas [...]" assistidas pelas comunidades. Nas quais "[...] os homens podiam se reunir em pequenos grupos para discutir política, trocar cavalos, envolver-se em confusões e debater as questões mais importantes do dia". ${ }^{41}$ De acordo com Harry S. Laver, essas aglomerações transcendiam o alívio que advinha da quebra da rotina:

$[\mathrm{O}] \mathrm{s}$ eventos da milícia encorajavam o culto à identidade nacional [através] de uma associação pessoal com os Estados Unidos, [simultaneamente] reforçando as hierarquias sociais de classe, gênero e raça, mantendo a hegemonia dos homens brancos. ${ }^{42}$

Por volta de 1850, o sentimento antiprofissional e pró-miliciano era forte na maioria dos setores políticos, incluindo o emergente partido Republicano. Líderes republicanos como Simon Cameron, William Seward, Henry Wilson, Salomon Chase e o próprio Abraham Lincoln haviam servido em companhias milicianas quando jovens e ainda viam a instituição como um ativo positivo da política americana. $\mathrm{O}$ antiprofissionalismo era reforçado pela doutrina Jacksoniana dos direitos dos estados, do governo parcimonioso e da virtude do homem comum. Às vésperas da Guerra Civil, a maioria desses importantes estadistas republicanos provavelmente subscreveria as crenças do linguista e político Albert Gallatin, que no início daquele mesmo século observou: "A distribuição do nosso pequeno exército em aquartelamentos distantes [...] é o melhor arranjo que pode ser feito para contornar aquele mal necessário". ${ }^{43}$

Anos 90, Porto Alegre, v. 22, n. 41, p. 83-111, jul. 2015 
A organização miliciana sancionava práticas democráticas que eram incompatíveis com uma hierarquia propriamente militar. Em muitos casos, os soldados elegiam seus oficiais de escalão mais baixo, um desafio às concepções modernas sobre disciplina e hierarquia. ${ }^{44}$ Essa visão de mundo sobreviveu às décadas iniciais e ainda era forte em meados do século XIX. No estado de Vermont, The Citizen Soldier, um jornal local dedicado aos interesses da milícia, resumiu as atitudes dos contemporâneos num editorial de 1840:

Os exércitos permanentes têm sido considerados hostis às liberdades civis em todas as épocas e países. A sua própria organização e profissionalismo os separam, tanto em sentimento como em interesse, da grande maioria da população. A sua imediata dependência do poder Executivo do país, e a sua subjeção aos seus desmandos, fazem dele uma ferramenta pronta para oprimir o povo, estabelecendo a tirania. ${ }^{45}$

Por volta de 1860 , as instituições militares refletiam a falta de controle do governo federal sobre os estados assim como a coexistência de duas formas de cidadania: a estadual, que prevaleceu durante todo o período anterior à Guerra Civil; e a nacional, que era muito menos importante e que só seria reforçada após a aprovação da $14^{a}$. Emenda à Constituição, em 1868. Num contexto doméstico no qual as principais lealdades dos cidadãos eram locais, conflitos entre os direitos dos estados e os interesses do governo federal intensificariam-se no contexto que levaria à eclosão da Guerra Civil, reacendendo debates que datavam do período constitucional. A questão militar, associada ao papel apropriado do estado nacional, continuaria no centro das discussões emergindo ao longo do conflito seccional.

\section{Resumindo}

A desconfiança dos colonos norte-americanos em relação aos exércitos permanentes decorria de vários fatores. Durante os últimos quarenta anos, os historiadores debateram sobre a origem dessas atitudes. Historiadores das ideias como Bernard Bailyn, Gordon 
Wood e J. G. A. Pocock enfatizaram o papel das ideologias dos Whigs radicais, derivadas das tradições republicano-libertárias inglesas do século XVII. Essas doutrinas antiabsolutistas, fortemente baseadas nas práticas puritanas, eram críticas das relações de subserviência que vinculavam os soldados aos seus oficiais nas organizações profissionais. Em situações como essa, um exército de despossuídos poderia facilmente ficar sob o controle de líderes ambiciosos. Mesmo entre os fazendeiros independentes (freeholders), o serviço militar requereria que os recrutas abrissem mão da sua independência, aceitando a subordinação a oficiais superiores, normalmente estranhos, não relacionados àqueles que eventualmente liderariam em combate. ${ }^{46}$

Críticas a essa abordagem "republicanista" foram apresentadas pelo trabalho de historiadores sociais, especialistas no período colonial, com fortes pesquisas empíricas sobre o assunto, tais como Don Higginbotham e John Shy. Esses pesquisadores sublinharam a importância das crenças comunitárias, conformadas por valores culturais protestantes, e as reações locais contrárias às intrusões militares. Esses mesmos historiadores reconheceram os limites da hostilidade no curso de eventos e condições relacionados aos períodos de guerra. De acordo com essa perspectiva, reações aos profissionais constituíram, quase sempre, o resultado do pragmatismo, ainda que considerações ideológicas não possam ser completamente descartadas. $\mathrm{O}$ fato de esses mesmos historiadores concentrarem suas pesquisas na primeira metade do século XVIII, quando ocorreu um estreitamento das relações militares com a Grã-Bretanha, não pode ser descartado.

Quaisquer que tenham sido as razões que fundamentaram as atitudes antiprofissionais, parece certo que a combinação de diferentes fatores práticos, reforçados por tradições libertárias, enfraqueceu as tradições militares na América Inglesa, fomentando uma tradição que permaneceria viva após a independência e a estruturação da república. Assim, circunstâncias materiais aliadas às ideias não conformistas reforçaram uma aversão por alistamentos de longo prazo, disciplina árdua e a existência de exércitos permanentes. A disciplina e a subordinação ameaçavam a autodeterminação e o não conformismo que constituíam crenças fortes entre a maioria dos habitantes brancos. A forte correlação entre a composição 
da oficialidade e o pertencimento à liderança local reforçaram a influência dos status e do poder das localidades na designação das lideranças milicianas enquanto os oficiais do exército provinham de um espectro amplo da sociedade, impedindo que se cristalizasse no exército o domínio de uma casta originária de uma única classe social ou do predomínio de uma região. Ordem e estabilidade não apenas encorajavam uma sociedade em expansão como também a evolução das atividades econômicas num período de transição entre uma produção de subsistência e um mercado cada vez mais complexo. A milícia fornecia o apoio e a energia adequados para essa etapa de transição. Os voluntários estavam mais dispostos a servir com pessoas conhecidas, lideradas por um respeitado membro da coletividade - do que arriscar sua sorte se subordinando a estranhos. Um exército profissional era considerado incompatível com uma república de cidadãos. Assim sendo, as vantagens estratégicas trazidas pelos exércitos profissionais eram contrabalançadas por sérios argumentos que enfatizavam a ameaça a ambos: a estabilidade interna e a hierarquia social. Aqueles preocupados com a hierarquia associavam a existência de exércitos aos tumultos, às revoltas e à anarquia. A maior parte dessas preocupações derivava de suspeitas longamente arraigadas a respeito da ameaça fornecida pelas classes populares, especialmente pelo ajuntamento de imigrantes recém-chegados, que seriam presas fáceis de qualquer processo mais dilatado de arregimentação. Aqueles preocupados com a estabilidade temiam as restrições à ordem pública e à virtude cívica, decorrentes do estabelecimento de instituições centralizadas comandadas por oficiais ambiciosos. O exército permanente era, sobretudo, considerado como uma instituição cara e não confiável, cujo poder e influência trariam riscos permanentes à liberdade e à manutenção da ordem. A desconfiança sobre a viabilidade de uma ferramenta essencial à construção das nações modernas tornou o processo de construção do estado nos EUA muito distinto das trajetórias percorridas pela França e pela Prússia, para citar apenas dois exemplos importantes do panorama europeu.

Mas as soluções locais não seriam compatíveis com as necessidades militares de uma república extensa, quando confrontada com uma rebelião separatista. A organização militar descentralizada 
mostrar-se-ia insuficientemente capacitada para lidar com os desafios do separatismo Confederado, quando a maioria dos estados do Sul decidiu separar-se da União. Nesse momento, a Guarda Nacional dividiu-se segundo os interesses dos estados em relação à crise política, enfraquecendo a capacidade do estado nacional de sufocar a rebelião em seus estágios iniciais.

Quando a Guerra Civil teve início, a capacidade da União para construir um exército forte estava limitada pelas tradições da cultura cívica americana. Por volta de 1860, a maioria dos americanos era hostil à ideia de um exército permanente e centralizado, na mesma medida em que se mostravam refratários a um estado centralizado e a uma burocracia fiscal. Localismo, antimilitarismo e defesa das liberdades individuais eram fortemente considerados. Consequentemente, a interferência governamental sobre esses valores era vista com alarme pela maioria da população. Nos Estados Unidos oitocentistas, o nacionalismo combinava descentralização, localismo e supremacia branca sob formas desconhecidas no Brasil durante a mesma época.

\section{THE MILITIA EXPERIENCE IN BRITISH NORTH AMERICA: ANTI- -MILITARISM OR PRAGMATISM?}

Abstract: This article analyses the militia experience in British colonial America and the early US first republic. It emphasizes the role of antimilitarism in shaping the character of US military tradition in the antebellum period as well as the civilian control of the military establishment. I relate this influence to the social aversion to despotism coming from British political tradition, stressing conflicts between central, local and state authorities and the problems they posed to creating a Professional army.

Keywords: Militias. United States. Anti-Militarism. Citizenship. Self-Government.

\section{Notas}

${ }^{1}$ Sobre os padrões diversos da colonização, BAILYN, Bernard. The peopling of British North America, p. 45-86, 1998.

${ }^{2}$ SHY, John. American Military Experience, p. 210-215, 1971.

${ }^{3}$ ERTMAN, Thomas. Birth of the Leviathan, p. 90-223, 1997.

Anos 90, Porto Alegre, v. 22, n. 41, p. 83-111, jul. 2015 
${ }^{4}$ Charles Tilly definiu a trajetória percorrida pelos estados europeus como "[...] uma acumulação e concentração de poderes coercitivos", num paralelo com a discussão de Karl Marx sobre a "acumulação primitiva". Ver TILLY, Charles. Logics of Capital and Coercion. Coercion, Capital, and European States, p. 16-19.

${ }^{5}$ CRAMER, Clayton E. Armed America, p. 3-90.

6 "Soldiers when they choose to be". John Whiteclay Chambers II, To Raise an Army, p. 13-39. Ressalte-se que as cartas colôniais associavam frequentemente a cidadania à posse de armas de fogo.

${ }^{7}$ BAILYN, Bernard. Barbarous Years, p. 97-116, 2003.

8 " $[\ldots]$ we goe out in the morning, we know not wheter we shall ever returne; working with out Hoe in hand, and ou Peece or Sword in the other". Richard Frethirne aos pais, 20 de abril de 1683. Citado em Edward Aber e A. G. Bradley (Eds.). Travels and Works of Captain John Smith. v. I, p. 19, 1910.

9 “" [...] we having burnt down almost all their Wigwarms, as also their Corn that we could find, they thereby have less Shelter and less Subsistance left them, which Misery of theirs is much aggravated by [the] great Snow". Charles H. Lincoln (Ed.). Narratives of the Indian Wars, p. 61, 1913.

${ }^{10}$ SHY, John. The American Military Experience: History and Learning, p. 205-228; HIGGINBOTHAM, Don. The Early American Way of War: Recognizance and Appraisal, p. 200-273; CARP, Wane. Early American Military History: A review of Recent Work, p. 259-284. Para uma análise mais recente da historiografia sobre as questões militares no período colonial e seus impactos na Guerra de Independência, RESCH, John; SARGENT, Walter. Changing meanings of the American Revolution, p. 291-300, 2006.

${ }^{11}$ SHY, John. American Military Experience, 10, 1971.

${ }^{12}$ A fragilidade militar da Virgínia constitui tópico constante da historiografia colonial americana. Para um trabalho recente, explorando os temores senhoriais decorrentes da presença de escravos, TAYLOR, Alan. The Internal Enemy,p. 317-350, 2013.

${ }^{13}$ Para comparações com a situação hispano-americana, ver Ben Vision III. Bearing Arms for His Majesty, p. 173-220, 2002; LASSO, Marixa. Race War and Nation in Caribbean Gran Colombia, Cartagena, 1810-1832, 2006; BLANCHARD, Peter. The Language of Liberation: Slave Voices in the Wars of Independence. Para a exclusão dos negros da milícia, ver SHEA, William L. The Virginia Militia in the Seventeenth Century, p. 108. ${ }^{14}$ SHEA, William L.; The Virginia Militia in the Seventeenth Century. op. cit., p. 130, 1983.

${ }^{15}$ Os exércitos provinciais, de forma distinta das milícias, foram organizados por cada um dos treze governos coloniais em resposta às cotas anuais estabelecidas pelos comandantes e chefe britânicos. Para maiores detalhes, ver: SYRETT, David. American Colonial Governments and the Raising of Provincial Troops during the Seven years War.

Anos 90, Porto Alegre, v. 22, n. 41, p. 83-111, jul. 2015 


\section{Vitor Izecksohn}

${ }^{16}$ SELESKY, Harold E. War and Society in Colonial Connecticut, p. 144, 1990.

${ }^{17}$ ANDERSON, Fred. A People's Army, p. 28, 1996.

${ }^{18} \mathrm{Na}$ literatura James Fenimore Cooper retratou a Guerra dos Sete anos em $O$ último dos moicanos, enfatizando as tensões entre os milicianos e o exército regular.

${ }^{19}$ SELESKY, Harold E. War and Society in Colonial Connecticut, p. 74, 1996.

${ }^{20}$ SHY, John. Looking Backward, Looking Forward, p. 10.

21 “[V]ery indifferent men, this country affording no better". MCCARDELL, Lee. Il-Starred General: Braddock of the Coldstream Guards, p. 212. "Obstinate and Ungovernable People, and Uterly Unacquainted with the Nature of Subordination in General [...]". Apud LEACH, Douglas Edward. Roots of Conflict: British Armed Forces and Colonial Americans, 1677-1773, p. 130-131, 1989.

${ }^{22}$ ROYSTER, Charles. A Revolutionary People at War: the Continental Army and the American Character, p. 11.

23 “[...] as if in an Enemy's Country". Apud ARCHER, Richard. As if an Enemy's Country: The British Occuation of Boston and the Origins of the Revolution, p. xvii.

${ }^{24}$ COUNTRYMAN, Edward. The American Revolution, p. 7, 2003.

${ }^{25}$ LEHRMAN, Gilder. Institute of American History (GLCO) 6130 - The Loyalty and devotion of colored Americans (panfleto). Boston, publicado por WALLCUT, R. F. n. 221, Washington street, re-impresso em 1861.

${ }^{26}$ A esse respeito, ver GILBERT, Alan. Black Patriots and Loyalists: Fighting for Emancipation in the War of Independence, especialmente p. 15-45, p. 95-192.

${ }^{27}$ BASSET, John Spencer (Ed.). Correspondence of Andrew Jackson, p. 51-54.

${ }^{28}$ A luta entre John Andams e Alexander Hamilton a respeito do "Novo Exército" em 1798 dividiu o Partido Federalista, contribuindo para sua derrota em 1800. SKELTON, Will B. Officers and Politicians, p. 25.

${ }^{29}$ HUNTINGTON, Samuel. The Soldier and the State, p. 169, 1981.

${ }^{30}$ Apêndice aos Annals of Congress, $1^{\text {st }}$ Congress, $1^{\text {st }}$ Sessions, p. 1392.

${ }^{31}$ KRAAY, Hendrik. Arming Slaves in Brazil from the Seventeenth century to the Nineteenth Century, p. 162-167, 2006.

32 BERLIN, Ira et all.; The black military experience, p. 195, 1998.

${ }^{33}$ CHAMBERS, John Whiteclay. To Raise na Army..., op. cit., p. 29.

${ }^{34}$ Para análises dessa evolução, particularmente da relação entre pertencimento à milícia e participação política, ver MAHON, John K. History of the Militia and the National Guard, p. 78-96; ROWE, Mary Ellen. Bulwark of the Republic: He American Militia in the Antebellum West, especialmente, p.71-92, 2003; LAVER, Harry S. Rethinking the Social Role of the Militia: Community-Building in Antebellum Kentucky. 35 TOCQUEVILLE, Alex de. Democracy in America, p. 228, 1835.

${ }^{36}$ Ibid, Democracy in America, p. 228, 1835.

${ }^{37}$ Apud MAHON, John K.; The War of 1812, p. 32, 1991.

${ }^{38}$ SKOWRONEK, Stephen. Building a New American State: the expansion of national administrative capacities, 1877-1920, p. 85-120. 
${ }^{39}$ Apud EUSTACE, Nicole. 1812: War and the Passions of Patriotism, p. 72, 2012. ${ }^{40}$ MCKITRICK, Eric L. Party politics and the Union and Confederate War Efforts, p. 120. ${ }^{41}$ Apud ROHRBOUGHT, Malcon J. The Trans-Appalachian Frontier, p. 30. ${ }^{42}$ LAVER, Harry S. Rethinking the Social Role of the Militia, p. 780, 2002. ${ }^{43}$ Albert Gallatin, para sua esposa, 7 de julho de 1802. Apud COFFMAN, Edwad M. The Old Army, 1794-1798, p. 38.

${ }^{44}$ Para as relações entre o serviço nas milícias e a extensão de direitos políticos, ver PETERSON, Merril D. (Ed.). Democracy, Luberty and Propriety: The State Constitutional Conventions of the 1820's, p. 136-148; YAZAWA, Melvin Citizenship. In: GREENE, Jack P. (Ed.). Encyclopedia of American Political History: Studies of the Principal Movements and Ideas, v. I, p. 109-209, 1984.

${ }^{45}$ Citizen Soldier, v. I, n. 1, Norwich, VT, 22 de julho de 1840.

${ }^{46}$ BAILYN, Bernard. The Ideological Origins of the American Revolution, p. 354-358, 1992; WOOD, Gordon. The Creation of the American Republic, 1776-1787, p. 3-46; POCOCK, J. G. A. The Machiavellian moment: Florentine political thought and the Atlantic republican tradition, especialmente o capítulo XII, "The Anglicization of the Republic: Court, Country and Standing Army”, p. 401-422, 1924.

\section{Referências}

ABER, Edward; BRADLEY A. G. (Org.). Travels and Works of Captain John Smith. Vol. II. Edinburgo: J. Grant, 1910.

ANDERSON, Fred. A People's Army: Massachusetts Soldiers and Society in the Seven Year's War. Chapel Hill: The University of North Carolina Press, 1984.

BAILYN, Bernard. The Ideological Origins of the American Revolution. Cambridge: Harvard University Press, 1967. Reprint, 1992.

. The Peopling of British North America: An Introduction. New York: Vintage Books, 1986.

Barbarous years: the peopling of British North America: the Conflict of Civilizations, 1600-1675. New York: Alfred A. Knopf, 2012.

BASET, John Spencer (Org.). Correspondence of Andrew Jackson. Washington: DC, Carnegie Institution of Washington, 1926.

BERLIN, Ira et all. The Black Military Experience. In. Slaves no More. Three Essays on Emancipation and the Civil War. New York: Cambridge University Press, 1992. BLANCHARD, Peter. The Language of Liberation: Slave Voices in the Wars of Independence. Hispanic American Historical Review, v. 8. n. 23, 2002, p. 499-523.

Anos 90, Porto Alegre, v. 22, n. 41, p. 83-111, jul. 2015 


\section{Vitor Izecksohn}

CARP, Wane. 'Early American Military History: A review of Recent Work'. Virginia Magazine of History and Biography, 1986, p. 259-284.

CHAMBERS II, John Whiteclay. To Raise an Army: The Draft Comes to Modern America. New York: Free Press, 1987.

COFFMAN, Edward M. The Old Army: A Portrait of the American Army in Peacetime, 1794-1798. New York: Oxford University Press, 1986.

COOPER, James Fenimore. O Último dos Moicanos. Trad. Vera Lúcia Rodrigues. São Paulo: Germinal Editora, 2009.

COUNTRYMAN, Edward. The American Revolution. New York: Hill and Wang, 1985.

CRAMER, Clayton E. Armed America: The Remarkable Story of How and Why Guns Became as American as Apple Pie. Nashville: Nelson Current, 2009.

ERTMAN, Thomas. Birth of the Leviathan: Building States and Regimes in Medieval and Early Modern Europe. Cambridge/MA: Cambridge University Press, 1997.

EUSTACE, Nicole. 1812: War and the Passions of Patriotism. Filadélfia: University of Pennsylvania Press, 2012.

GILBERT, Alan. Black Patriots and Loyalists: Fighting for Emancipation in the War for Independence. Chicago: The University of Chicago Press, 2012.

HIGGINBOTHAM, Don. "The Early American Way of War: Recognizance and Appraisal". The William and Mary Quaterly, $3^{\text {rd }}$. Ser., v. 44, n. 2, 1987, p. 200-273.

HUNTINGTON, Samuel. The Soldier and the State: The Theory of Civil-Military Relations. New York: Vintage Books, 1957.

KRAAY, Hendrik. Arming Slaves in Brazil from the Seventeenth Century to the Nineteenth Century. In. BROWN, Chrostopher Leslie; MORGAN, Philip D. Arming Slaves: from classical times to the modern age. New Haven: Yale University Press, 2006, p. 146-179.

LASSO, Marixa. Race War and Nation in Caribbean Gran Colombia, Cartagena, 1810-1832. The American Historical Review. v. 111, n. 2, 1986, p. 336-361.

LAVER, Harry S. Rethinking the Social Role of the Militia: Community-Building in Antebellum Kentucky. The Journal of Southern History. v. LXVIII. n. 4, 2002, p. 777-816.

LEACH, Douglas Edward. Roots of Conflict. British Armed Forces and Colonial Americans, 1677-1773. Chapel Hill: University of North Carolina Press, 1986.

LINCOLN, Charles H. (Org.). Narratives of the Indian Wars, 1675-1699. New York: Scribner's Sons, 1913. 
MAHON, John K. The War of 1812. Gainesville: University of Florida Press, 1972. . History of the Militia and the National Guard. New York: Macmillan, 1983.

McCARDELL, Lee. Il-Starred General: Braddock of the Coldstream Guards. Pittsburgh: University of Pittsburg Press, 1958.

McKITRICK, Eric L. Party politics and the Union and Confederate War Efforts. In. CHAMBERS, William Nisbet; BURNHAM, Walter Dean (Orgs.). The American Party System: Stages of Political Development. New York: Oxford University Press, 1975.

PETERSON, Merril D. (Org.). Democracy, Liberty and Propriety: The State Constitutional Conventions of the 1820's. Indianápolis: Bobbs-Merril Co, 1966.

POCOCK, J. G. A. The Machiavellian moment: Florentine political thought and the Atlantic republican tradition. Princeton: Princeton University Press, 1975.

RESCH, John; SARGENT, Walter. Changing meanings of the American Revolution. Mobilization and Home Fronts. DeKalb: Illinois University Press, 2007.

ROHRBOUGH, Malcolm J. The Tran-Appalachian Frontier: People, Societies, and Institutions, 1775-1850. New York: Oxford University Press, 1978.

ROWE, Mary Ellen. Bulwark of the Republic: The American Militia in the Antebellum West. Westport/CT: Praeger, 2003.

SELESKY, Harold E. War and Society in Colonial Connecticut. New Haven: Yale University Press, 1990.

SHEA, William L. The Virginia Militia in the Seventeenth Century. Baton Rouge: Louisiana State University Press, 1983.

SHY, John. The American Military Experience: History and Learning. Journal of Interdisciplinary History. V. 1, n. 2, (Winter, 1971), p. 205-228.

. Looking Backward, Looking Forward. In. RESH, John; SARGENT, Walter (Orgs.).War \& Society in the American Revolution: Mobilization and Home Fronts. Dekalb: Northern Illinois University Press, 2007.

SKELTON, William B. Officers and Politicians: The Origins of Army Politics in the United States before the Civil War. Armed Foces \& Society. v. 6, n. 1, 1979, p. $22-48$.

SKOWRONEK, Stephen. Building a New American State: the expansion of national administrative capacities, 1877-1920, 1984, reprint. New York: Cambridge University Press, 1983. 


\section{Vitor Izecksohn}

SYRRET, David. American Colonial Governments and the Raising of Provincial Troops during the Seven years War. Journal of the Society for Army Historical Research, v. 18, n. 326, 2003, p. 96-113.

TAYLOR, Alan. Internal Enemy: Slavery and War in Virginia, 1772-1832. New York: W.W. Norton, 2013.

TILLY, Charles. Coercion, Capital, and European States, AD 990-1992. 1990, reprint. Cambridge: Blackwell, 1992

TOCQUEVILLE, Alex de. Democracy in America. 1848, reprint, Nova Iorque: Anchor Books, 1969.

VISION III, Ben. Bearing Arms for His Majesty: The Free Colored Militia in Colonial Mexico. Stanford: Stanford University Press

WOOD, Gordon. The Creation of the American Republic, 1776-1787. Chapel Hill: University of North Carolina Press, 1969.

YAZAWA, Melvin. Citizenship. In. GREENE, Jack P. (Org.). Encyclopedia of American Political History: Studies of the Principal Movements and Ideas. 3 vols. New York: Scribnner, 1984, v. I, p. 109-209.

Recebido em: 29/11/2014 Aprovado em: 03/02/2015 
